\title{
Identification of clinical phenotypes in knee osteoarthritis: a systematic review of the literature
}

\author{
A. Dell'Isola*, R. Allan, S. L. Smith, S. S. P. Marreiros and M. Steultjens
}

\begin{abstract}
Background: Knee Osteoarthritis (KOA) is a heterogeneous pathology characterized by a complex and multifactorial nature. It has been hypothesised that these differences are due to the existence of underlying phenotypes representing different mechanisms of the disease.

Methods: The aim of this study is to identify the current evidence for the existence of groups of variables which point towards the existence of distinct clinical phenotypes in the KOA population. A systematic literature search in PubMed was conducted. Only original articles were selected if they aimed to identify phenotypes of patients aged 18 years or older with KOA. The methodological quality of the studies was independently assessed by two reviewers and qualitative synthesis of the evidence was performed. Strong evidence for existence of specific phenotypes was considered present if the phenotype was supported by at least two high-quality studies.

Results: A total of 24 studies were included. Through qualitative synthesis of evidence, six main sets of variables proposing the existence of six phenotypes were identified: 1) chronic pain in which central mechanisms (e.g. central sensitisation) are prominent; 2) inflammatory (high levels of inflammatory biomarkers); 3) metabolic syndrome (high prevalence of obesity, diabetes and other metabolic disturbances); 4) Bone and cartilage metabolism (alteration in local tissue metabolism); 5) mechanical overload characterised primarily by varus malalignment and medial compartment disease; and 6) minimal joint disease characterised as minor clinical symptoms with slow progression over time.
\end{abstract}

Conclusions: This study identified six distinct groups of variables which should be explored in attempts to better define clinical phenotypes in the KOA population.

Keywords: Knee, Osteoarthritis, Phenotype, Sub-group, Clinical

\section{Background}

Osteoarthritis is the most common form of arthritis; it constitutes a leading cause of disability in the adult population [1] with the knee the most affected joint. Knee Osteoarthritis (KOA) is a heterogeneous pathology characterized by a complex and multifactorial nature [2]. This multifactorial aetiology contributes to the broad variation in symptoms presentation and treatment response that characterize the KOA subjects and constitutes a challenge for the identification of personalized and effective interventions. Therefore, in order to optimize treatment effect in KOA, the intervention should address

\footnotetext{
* Correspondence: andrea.delllsola@gcu.ac.uk

Institute of Applied Health Research/School of Health and Life Sciences, Glasgow Caledonian University, Glasgow G4 OBA, Scotland, UK
}

this variability and should be tailored to specific subgroups or phenotypes as highlighted in the NICE guidelines on KOA [3-6]. A phenotype in KOA can be defined as a collection of observable traits (i.e. aetiologic factors, risk factors) that can identify and characterize a subgroup in a defined population. The presence of distinct phenotypes within the KOA patient population would suggest distinct underlying causes and mechanisms, which could be highly relevant for understanding and treating the disease $[7,8]$.

Previous attempts to identify distinctive KOA phenotypes used different perspectives. Some researchers used disease progression to determine KOA phenotypes, while others looked at pain perception or the degeneration pattern of the cartilage [9-15]. Potentially, hundreds of phenotypes may be identified depending on the definition 
of phenotypes and on the variables selected. Each approach can be considered equally valid depending on the scope. Only studies focusing on the identification of clinical subgroups characterized by different disease mechanisms can be considered useful to improve treatment allocation and clinical management of the disease. If, as hypothesized, treatments Are highly effective only in one sub-type; the therapeutic effect of the intervention will be lost if tested in KOA population as a whole [4]. Therefore, the identification of risk and aetiologic factors that can identify specific clinical subtypes of KOA is an important starting point for the implementation of phenotyping research in clinical practice and may be critical for the improvement of treatment allocation and for the development of new treatment strategies.

The aim of this review is therefore to synthesize the current evidence for the existence of distinct sets of variables that may suggest the existence of clinical KOA phenotypes characterized by the presence of different risk and aetiologic factors.

\section{Methods}

\section{Information sources}

A systematic literature search was conducted in PubMed (Medline) for the period from 01/01/1984 to 29/04/ 2016. An additional manual search was completed by ADI from the references of the selected papers.

The research strategy was built up using the following key words: osteoarthritis, knee, phenotyp*, subgroup, cluster, "factor analysis". These terms were combined in the following way: osteoarthritis AND knee AND (phenotyp* OR subgroup OR cluster OR "factor analysis") (for further details see Additional file 1-A).

\section{Inclusion criteria}

Articles were included if: (1) the population involved (a subgroup of) patients over 18 years of age; (2) the population consisted of patients diagnosed with KOA; (3) the aim was to identify clinical phenotypes of patients with KOA; (4) the methodology and analysis were designed to identify phenotypes (e.g. cluster analysis using clinical variables) ; (5) the article was an original research report. Previous systematic reviews were excluded. In addition to the second criterion, studies that included patients with hip or hand OA other than KOA were included if: (1) they used biomarkers or other measures that are not joint specific, (2) the KOA subgroup represented more than $60 \%$ of the sample.

\section{Data selection process}

Article selection was made independently by two reviewers (ADI and MS) based on title and abstract according to the inclusion criteria. The final selection was made by the same two independent reviewers based on the full text. Disagreements between the two reviewers were resolved by the intervention of a third reviewer (SS); this procedure was adopted for both selection steps.

\section{Assessment of methodological quality (risk of bias)}

The methodological quality of the papers was assessed using an adaption of the standardized Hayden score [16] (Table 1) to identify the risk of bias affecting the validity of findings. All papers were reviewed by ADl and MS, with additional proportional reviews performed by RA, $\mathrm{SM}$, SS using block allocation with each reviewing $2 / 3$ of the final papers.

The risk of bias for each area was rated as low, moderate or high [16]. Studies that had a high risk of bias in at least one of the area assessed were considered to have an overall high risk of bias and regarded as sources of low quality evidence used only to support the findings of other (i.e. high quality) studies. Studies with low to moderate risk of bias and appropriate design were considered sources of strong evidence.

\section{Data-extraction analysis}

The data from each study were extracted by two reviewers (ADI, MS) and included number of patients, clustering method and subgroups identified. Additionally, the prevalence of each phenotype was extracted where possible.

\section{Identification of phenotypes}

In this systematic review we adopted a tailored data analysis process in order to deal with the broad variation in the methodologies of the studies included. This process shares some similarities with the directed content analysis method [17]. Key variables for each phenotype reported in the included studies were extracted. Using the theory and previous evidence, we assigned each key variable to a category (e.g. biomechanical, inflammatory, metabolic) indicating the underlying disease mechanism represented by that specific variable.. Variables (e.g. radiographic features, pain sensitization) were considered to suggest similar disease mechanisms and classified in the same category if: (1) It was specifically stated by the author of the paper (e.g. two subgroups extracted from two different studies were reported by the respective authors as representing the same phenotype); (2) the association of the reported characteristic to a specific pathophysiologic mechanism had been reported in previous studies investigating disease mechanisms and risk factors (e.g. malalignment consistent with compartment degeneration has previously been reported as a biomechanical mechanism responsible for KOA development). Each phenotype was then classified in the category indicated by the variable that characterized it. A phenotype was considered supported by evidence when at least two 
Table 1 Adaptation of the Hayden score for the evaluation of the risks of bias

\begin{tabular}{ll}
\hline Areas of potential bias & Explanation and Adaptation \\
\hline $\begin{array}{ll}\text { (1) Participation } & \text { Source population and characteristic of the sample } \\
\text { (2) Study attrition } & \text { Loss to follow up } \\
\text { (3) Measurement of prognostic } & \text { A clear definition or description of the prognostic factor measured is provided and adequately reported. } \\
\text { Adaptation: We considered as prognostic factor the variable chosen in the study to classify the patients } & \text { and define the phenotypes } \\
\text { (4) Outcome measurement } & \text { A clear definition of the outcome of interest is provided and the outcome methods are valid and reliable. } \\
& \begin{array}{l}\text { Adaptation: we considered the variable used to define the difference between subgroups as outcome } \\
\text { measures }\end{array} \\
\text { (5) Confounding factors } & \text { Are confounders present in the study; confounding factors are accounted for in the study design } \\
\text { (6) Analysis } & \text { Data analysis and data presentation }\end{array}$ \\
\hline
\end{tabular}

${ }^{a}$ : areas of potential bias adapted to match the design of the studies included

studies with low risk of bias identified a phenotype under the same category. If a phenotype was reported in only a single study this was not considered sufficient evidence to include this phenotype in the final list of phenotypes identified in this review.

\section{Results}

\section{Description of the included studies}

The initial literature search identified 841 articles. Three additional papers were identified through a manual search of the references. After screening for title and abstract, 781 papers were excluded. The full texts for the remaining 63 articles were assessed for inclusion. From this list, 25 articles matched the inclusion criteria and were included in the systematic review (Fig. 1) [7-9, 18-39]. For an overview of the studies included see Table 2. (For further details see Additional file 1).

\section{Quality assessment}

The quality assessment resulted in 21 papers with low or moderate risk of bias (considered to be high quality studies) and four papers with a high risk of bias for at least one of the six areas reviewed, which were considered to be low quality studies (Table 3).

\section{Phenotypes}

A total of 79 phenotypes were reported in the included studies. Of those, 42 phenotypes were reported in a single study only and therefore not taken forward into the qualitative evidence synthesis. The remaining 37 subgroups were matched and combined into six main groups of variables that suggest the existence of different mechanisms in the KOA population: chronic pain; inflammatory mechanisms; metabolic mechanisms of bone and cartilage local to the joint, metabolic syndrome; mechanical

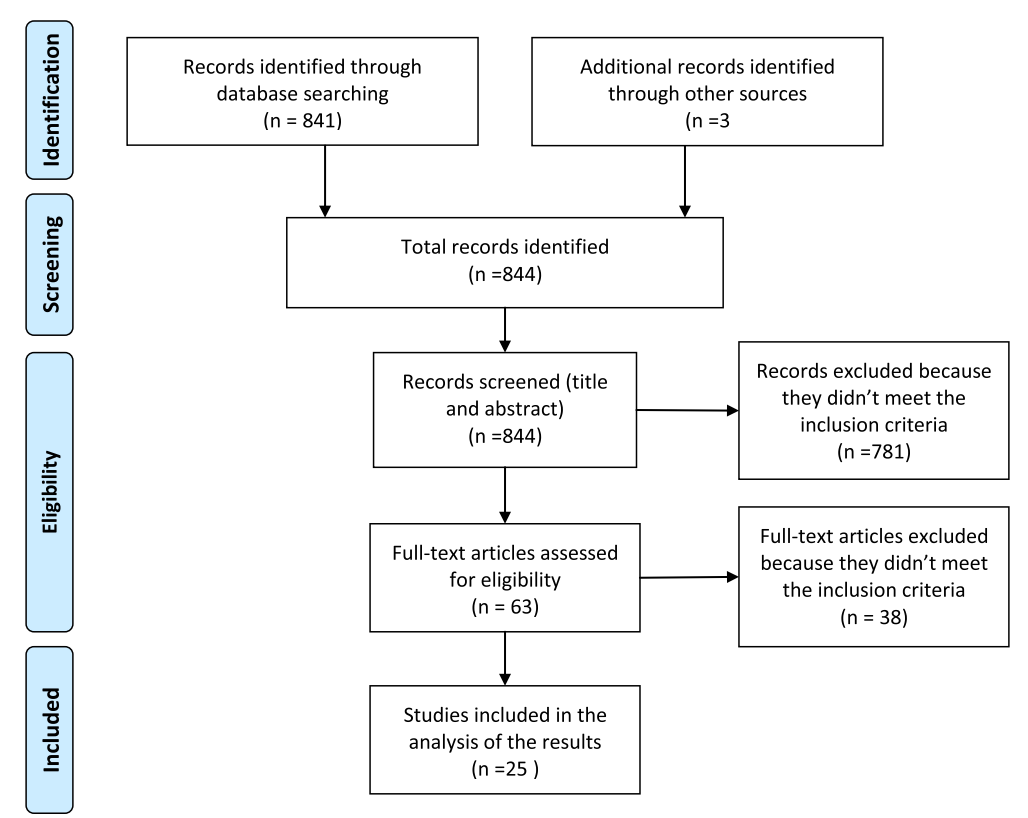

Fig. 1 Flow chart of the study selection process for eligible studies in the systematic review 
Table 2 Description of the papers

\begin{tabular}{|c|c|c|c|c|c|c|c|c|c|c|c|}
\hline \multirow[t]{2}{*}{ Author } & \multirow[t]{2}{*}{ Type of research } & \multirow[t]{2}{*}{ Type of study } & \multirow[t]{2}{*}{ Analysis } & \multirow[t]{2}{*}{ Participants } & \multirow[t]{2}{*}{ Control } & \multicolumn{6}{|l|}{ Subgoups } \\
\hline & & & & & & Chronic pain & Inflammatory & $\begin{array}{l}\text { Metabolic } \\
\text { syndrome }\end{array}$ & $\begin{array}{l}\text { Bone and } \\
\text { cartilage } \\
\text { metabolism }\end{array}$ & $\begin{array}{l}\text { Mechanical } \\
\text { overload }\end{array}$ & $\begin{array}{l}\text { Minimal } \\
\text { joint } \\
\text { disease }\end{array}$ \\
\hline Attur 2011 [18] & $\begin{array}{l}\text { Genetic/gene } \\
\text { expression }\end{array}$ & Cohort (prosp) & $\begin{array}{l}\text { complete } \\
\text {-linkage } \\
\text { hierarchical } \\
\text { clustering }\end{array}$ & $\begin{array}{l}1: 41^{a} \\
2: 36^{a} \\
3: 86^{a}\end{array}$ & $\begin{array}{l}1: 25^{\mathrm{a}} \\
2: 0^{\mathrm{a}} \\
3: 12^{\mathrm{a}}\end{array}$ & - & $\begin{array}{l}1: 16 / 41=39 \% \\
2: 8 / 36=22 \% \\
3: 33 / 86=38 \%\end{array}$ & - & - & - & - \\
\hline Bae 2010 [19] & $\begin{array}{l}\text { Imaging } \\
\text { (photography) }\end{array}$ & Cross sectional & $\begin{array}{l}\text { K-means } \\
\text { cluster } \\
\text { analysis }\end{array}$ & 127 & - & - & - & - & - & $20 \%^{b}$ & \\
\hline Berry 2010a [20] & Biomarker & Cohort (prosp) & $\begin{array}{l}\text { Mann-Whitney } \\
u, x^{2} \text {, Multiple } \\
\text { regression analysis }\end{array}$ & 117 & - & - & - & - & $\begin{array}{l}\text { Prevalence } \\
\text { not reported }\end{array}$ & - & - \\
\hline Berry 2010b [21] & Biomarker & Cohort (prosp) & $\begin{array}{l}\text { Mann-Whitney u, } \\
\text { Multiple regression } \\
\text { and logistic regression } \\
\text { analysis }\end{array}$ & 117 & - & - & - & - & - & - & $\begin{array}{l}\text { Prevalence } \\
\text { not reported }\end{array}$ \\
\hline $\begin{array}{l}\text { Blumnenfeld } \\
2013 \text { [22] }\end{array}$ & Biomarker & Cohort (prosp) & $\begin{array}{l}\text { Binary logistic } \\
\text { regression analysis }\end{array}$ & $\begin{array}{l}\text { Different in } \\
\text { different } \\
\text { analysis }\end{array}$ & $\begin{array}{l}\text { Different } \\
\text { in different } \\
\text { analysis }\end{array}$ & - & - & - & $\begin{array}{l}\text { Prevalence } \\
\text { not reported }\end{array}$ & - & - \\
\hline $\begin{array}{l}\text { Cruz-Almeida } \\
2013 \text { [23] }\end{array}$ & $\begin{array}{l}\text { Lab experimental } \\
\text { (non-biomech) }\end{array}$ & Cross-sectional & $\begin{array}{l}\text { Hierarchical cluster } \\
\text { analysys }\end{array}$ & 194 & - & $32 / 194=16 \%$ & - & - & - & - & - \\
\hline Doss 2007 [24] & Biomarker & Cross-sectional & Mann-Whitney & 49 & - & - & $8 / 49=16 \%$ & - & - & - & - \\
\hline $\begin{array}{l}\text { Egsgaard } \\
2015 \text { [25] }\end{array}$ & Biomarker & Case control & $\begin{array}{l}\text { Principal component } \\
\text { analysis/Hierarchical } \\
\text { cluster analysis }\end{array}$ & 216 & 64 & $41 / 212=19 \%$ & - & - & - & - & - \\
\hline $\begin{array}{l}\text { Fernández-Tajes } \\
2014 \text { [26] }\end{array}$ & Genetics & Case control & $\begin{array}{l}\text { Cluster analysys } \\
\text { (unsupervised) }\end{array}$ & 23 & 18 & - & $7 / 23=30 \%$ & - & - & - & - \\
\hline Holla 2013 [27] & Epidemiology & Cohort (prosp) & $\begin{array}{l}\text { Latent class } \\
\text { growth analysis }\end{array}$ & 697 & - & - & - & - & - & - & $330 / 697=47 \%$ \\
\hline $\begin{array}{l}\text { Jenkins } 2015 \\
\text { [28] }\end{array}$ & Epidemiology & $\begin{array}{l}\text { Secondary data } \\
\text { analysis }\end{array}$ & $\begin{array}{l}\text { Hierarchical and } \\
\mathrm{k} \text {-means cluster } \\
\text { analysis }\end{array}$ & 75 & - & - & - & - & - & - & $\begin{array}{l}\text { Prevalence not } \\
\text { reported }\end{array}$ \\
\hline $\begin{array}{l}\text { Kerkhof } 2008 \\
\text { [29] }\end{array}$ & Genetics & Cross sectional & $\begin{array}{l}x^{2}, \text { OR, ANCOVA, } \\
\text { meta-analysis of } \\
\text { existing cohorts }\end{array}$ & 4993 & - & - & - & - & - & - & - \\
\hline Kinds 2013 [9] & Imaging & Cohort (prosp) & $\begin{array}{l}\text { Hierarchical } \\
\text { cluster analysys }\end{array}$ & 336 & - & - & - & - & - & - & $108 / 417=26 \%$ \\
\hline King 2013 [30] & $\begin{array}{l}\text { Lab experimental } \\
\text { (non-biomech) }\end{array}$ & Case control & ANCOVA & 209 & 107 & $\begin{array}{l}\text { Subgroups } \\
\text { splitted using } \\
\text { mean value of } \\
\text { womac } \\
\text { (percentage } \\
\text { not reliable) }\end{array}$ & - & - & - & - & - \\
\hline
\end{tabular}


Table 2 Description of the papers (Continued)

\begin{tabular}{|c|c|c|c|c|c|c|c|c|c|c|c|}
\hline Knoop 2011 [7] & Epidemiology & $\begin{array}{l}\text { Secondary } \\
\text { data analysis }\end{array}$ & $\begin{array}{l}\text { K-means luster } \\
\text { analysis }\end{array}$ & 842 & - & $\begin{array}{l}83 / 841=10 \% \\
\text { (only } \\
\text { depression) }\end{array}$ & - & $\begin{array}{l}168 / 841=22 \% \\
\text { (only obese) }\end{array}$ & - & $189 / 841=22 \%$ & $140 / 841=17 \%$ \\
\hline $\begin{array}{l}\text { Murphy } \\
2011[31]\end{array}$ & Epidemiology & Cross-sectional & $\begin{array}{l}\text { Hierarchical } \\
\text { cluster analysis }\end{array}$ & 129 & - & $45 / 125=36 \%$ & - & - & - & - & - \\
\hline $\begin{array}{l}\text { Otterness } \\
2000 \text { [32] }\end{array}$ & Biomarker & Case control & $\begin{array}{l}\text { Principal } \\
\text { component } \\
\text { analysis }\end{array}$ & 39 & 21 & - & $\begin{array}{l}\text { Prevalence not } \\
\text { reported }\end{array}$ & - & $\begin{array}{l}\text { Prevalence not } \\
\text { reported }\end{array}$ & - & - \\
\hline $\begin{array}{l}\text { Pereira } \\
2013 \text { [33] }\end{array}$ & Epidemiology & Cross-sectional & $\begin{array}{l}\text { T-test, OR, } \\
\text { logistic } \\
\text { regression }\end{array}$ & 663 & - & $\begin{array}{l}\text { Prevalence } \\
\text { not reported }\end{array}$ & - & - & - & - & - \\
\hline $\begin{array}{l}\text { Roemer } \\
2012 \text { [34] }\end{array}$ & Imaging & Cross sectional & OR & 1248 & - & - & - & - & $\begin{array}{l}1248 \text { subjects/ } \\
0,2 \% \\
\text { hypertrophic- } \\
1.3 \% \text { atrophic }\end{array}$ & - & - \\
\hline $\begin{array}{l}\text { Sowers } \\
2002[35]\end{array}$ & Biomarker & Cohort & ANOVA, $x^{2}$ & 1025 & - & - & - & $11 \%^{\mathrm{b}}$ & - & - & - \\
\hline $\begin{array}{l}\text { Van der Esch } \\
2015 \text { [36] }\end{array}$ & Epidemiology & $\begin{array}{l}\text { Secondary } \\
\text { data anlysis }\end{array}$ & $\begin{array}{l}\text { K-means } \\
\text { cluster analysis }\end{array}$ & 551 & - & $\begin{array}{l}86 / 551=15.6 \% \\
\text { (only depression) }\end{array}$ & - & $\begin{array}{l}81 / 551=15 \% \\
\text { (only obese) }\end{array}$ & - & $\begin{array}{l}114 / 551= \\
20.6 \%\end{array}$ & $154 / 551=28 \%$ \\
\hline $\begin{array}{l}\text { Van Spil } \\
2012[37]\end{array}$ & Biomarker & Cohort (prosp) & $\begin{array}{l}\text { Principal } \\
\text { component } \\
\text { analysis, multiple } \\
\text { linear regression } \\
\text { (interaction terms) }\end{array}$ & 1002 & - & - & $\begin{array}{l}\text { Prevalence not } \\
\text { reported }\end{array}$ & - & $\begin{array}{l}\text { Prevalence not } \\
\text { reported }\end{array}$ & - & - \\
\hline $\begin{array}{l}\text { Waarsing } \\
2015[8]\end{array}$ & Epidemiology & $\begin{array}{l}\text { Secondary } \\
\text { data analysis }\end{array}$ & $\begin{array}{l}\text { Latent class } \\
\text { cluster analysis }\end{array}$ & 518 & - & - & - & $\begin{array}{l}27 \% \text { (group with } \\
\text { hypertension and } \\
\text { higher BMI) }\end{array}$ & - & $\begin{array}{l}15 \% \text { (lateral } \\
\text { degeneration) } \\
12 \% \text { (previous } \\
\text { injuries) }\end{array}$ & $47 \%^{b}$ \\
\hline $\begin{array}{l}\text { lijima } 2015 \\
\text { [38] }\end{array}$ & Epidemiology & Cross sectional & $\begin{array}{l}\text { Multiple Logistic } \\
\text { regression Analysis }\end{array}$ & 266 & - & - & - & - & - & $\begin{array}{l}26 / 266=9.7 \% \\
\text { (static + dinamic } \\
\text { malalignment) }\end{array}$ & - \\
\hline $\begin{array}{l}\text { Kittelson } \\
2015 \text { [40] }\end{array}$ & Epidemiology & $\begin{array}{l}\text { Secondary } \\
\text { data analysis }\end{array}$ & Latent class analysis & 3494 & - & $337 / 3494=9.6 \%$ & - & - & - & - & - \\
\hline
\end{tabular}

: this study is composed of 3 cohorts, the results obtained in the first cohort were replicated in the other two to validate the results

$b_{\text {: Only percentage reported }}$ 
Table 3 Risk of bias assessment adapted from Hayden et al

\begin{tabular}{|c|c|c|c|c|c|c|c|}
\hline \multirow[b]{2}{*}{ Author } & \multicolumn{6}{|l|}{ Risk of Bias } & \multirow[b]{2}{*}{ Total Score } \\
\hline & Participation & Attrition & Prognostic Factors & Outcome & Confounding & Analysis & \\
\hline Attur 2011 [18] & Low & Low & Low & Low & Moderate & Low & Low \\
\hline Bae 2010 [19] & Moderate & N/A & Low & Low & Moderate & Low & Low \\
\hline Berry 2010a [20] & Moderate & Moderate & Low & Low & Moderate & Moderate & Low \\
\hline Berry 2010b [21] & Low & Low & Low & Low & Moderate & Low & Low \\
\hline Blumnenfeld 2013 [22] & Low & Moderate & Moderate & Moderate & Moderate & Moderate & Low \\
\hline Cruz-Almeida 2013 [23] & Moderate & N/A & Low & Low & Moderate & Low & Low \\
\hline Doss 2007 [24] & Moderate & N/A & Low & Moderate & Moderate & Low & Low \\
\hline Egsgaard 2015 [25] & Moderate & N/A & Low & Low & High & Low & High \\
\hline Fernández-Tajes 2014 [26] & Moderate & N/A & Low & Moderate & Moderate & Moderate & Low \\
\hline Holla 2013 [27] & Moderate & Low & Low & Low & Low & Low & Low \\
\hline Jenkins 2015 [28] & High & N/A & Moderate & Moderate & High & Moderate & High \\
\hline Kerkhof 2008 [29] & Low & Low & Low & Low & Moderate & Low & Low \\
\hline Kinds 2013 [9] & Moderate & Low & Low & Low & Moderate & Moderate & Low \\
\hline King 2013 [30] & High & N/A & High & Low & High & Low & High \\
\hline Knoop 2011 [7] & Low & N/A & Low & Low & Low & Moderate & Low \\
\hline Murphy 2011 [31] & Moderate & N/A & Low & Moderate & Moderate & Low & Low \\
\hline Otterness 2000 [32] & Moderate & N/A & Low & Moderate & Moderate & Moderate & Low \\
\hline Pereira 2013 [33] & Low & N/A & Moderate & Low & Moderate & Low & Low \\
\hline Roemer 2012 [34] & Low & N/A & Low & Low & Moderate & Moderate & Low \\
\hline Sowers 2002 [35] & Moderate & Low & Low & Low & Moderate & Moderate & Low \\
\hline Van der Esch 2015 [36] & Low & N/A & Low & Low & Moderate & Low & Low \\
\hline Van spil 2012 [37] & Moderate & N/A & Low & Low & Moderate & Low & Low \\
\hline Waarsing 2015 [8] & Low & N/A & Low & Low & Low & Low & Low \\
\hline lijima 2015 [38] & Moderate & N/A & Low & Low & High & Low & High \\
\hline Kittelson 2015 [40] & Low & N/A & Low & Low & Low & Low & Low \\
\hline
\end{tabular}

N/A not applicable, the specific area of assessment was not applicable to the study

overload; and minimal joint disease (Additional file 1: Table S1 and S2). These mechanisms may be responsible for the disease in specific subgroup or phenotypes. The six main sets of variables that emerged from the literature are indicative of different disease aetiology with the exception of the minimal joint disease phenotype that classifies the subjects based on the disease progression. Only one paper reported negative results, founding no evidence for the existence of distinct phenotypes within the KOA patient population [29]. An overview of the variables extracted from each paper is provided in Table 2 and in the Additional file 1.

\section{Chronic pain}

Six cross sectional studies with low risk of bias, $[7,23,31$, $33,36,40]$ indicating the central nervous system and alterations in pain neurophysiology as key factors in the disease pathophysiology, were considered to support a chronic pain phenotype. Two additional studies with high risk of bias demonstrated similar findings. A chronic pain phenotype was defined using variables associated with central sensitisation $[23,40]$ (e.g. quantitative sensory testing (QST) [23]); pain and psychological profiling [31, 33]. The included studies demonstrated a high prevalence of lower pain pressure threshold and enhanced mechanical pain responses to temporal summation in several sites, suggesting full manifestation of peripheral spreading and central sensitization in a particular subgroup of KOA subjects. Moreover, the presence of psychological distress; poor coping style; sleep disturbance; fatigue; widespread pain and illness burden signify the existence of complex mechanisms that involve the entire body rather than the knee as the "target" of the disease $[23,25,31,40]$. These features have a prevalence of $16 \%$ to $19 \%$ in the KOA samples used in the aforementioned studies.

\section{Inflammatory KOA}

Two cohort studies and three cross-sectional studies with low risk of bias identified specific subgroups of patients suggesting the existence of an inflammatory KOA 
phenotype, the prevalence of which varies in the different samples from $16 \%$ to $30 \%[18,24,26,32,37]$. Attur et al. found a subgroup of KOA patients in which a gene overexpression of inflammatory cytokines is present (Interleukin-1B [IL-1ß], Interleukin-8 [IL-8], cycloxygenase 2[COX-2], GRO 2, macrophage inflammatory protein-1 $\alpha$ [MIP-1 $\alpha]$ and $-1 \beta$ [MIP-1 $\beta]$ ) [18]. These patients had a higher level of pain at the baseline and experienced faster radiographic progression compared to the group with cytokine underexpression. Furthermore a higher cytokine IL-6 concentration in the synovial fluid has been found in a subgroup of people undergoing a total knee (and hip) replacement [24]. The same cytokine has also been found to be associated with other inflammation markers (C-reactive protein [CR-P], tumor necrosis receptor type I [TNFI] and tumor necrosis receptor type II [TNFII], eosinophilic cationic protein $[E C P])$ in an inflammatory phenotype identified through a serum analysis [32]. Other inflammatory biomarkers (Serum III procollagen peptide [sPIIINP], serum hyaluronic acid [sHA], sCOMP) characterise a subgroup found by van Spil et al. with a higher synovial activity [37].

\section{Metabolic syndrome}

A metabolic phenotype characterized by variables suggesting that a systemic metabolic syndrome contributes significantly to the disease was supported by the literature Two longitudinal studies and two cross-sectional studies, all with low risk of bias (Tables 2, 3 and 4) $[7,35-37]$, suggest the existence of specific subgroups of patients characterized by a higher prevalence of metabolic factors (obesity, diabetes, hypertension and dyslipidemia) and a specific biomarker profile (plasma leptin [pLeptin], High-Sensitivity C-RP, erythrocyte sedimentation rate [ESR]) [7, 35-37]. These findings suggest the existence of a metabolic syndrome phenotype.

\section{Bone and cartilage metabolisms}

Five studies (three longitudinal studies; two crosssectional studies) reported subgroups of participants with alterations in bone and cartilage metabolism within the knee joint [20, 22, 32, 34, 37]. Berry et al. found an association between CTX-I; NTX-I and reduced cartilage lost in two subgroups, one characterized by high levels of osteocalcin and the other by high levels of PINP [20]. Van Spil et al. and Blumenfeld et al. found a cluster of biomarkers associated with bone and cartilage metabolism (uCTX-I, uCTX-II, uNTX-I, sPINP, sOC, sCOMP) $[22,37]$. Additionally, Otterness et al. identified three metabolic subgroups using bone markers (bone sialoprotein, hydroxylysyl pyridinoline, lysyl pyridinoline [BSP, HP, LP], putative markers of cartilage anabolism (carboxypropeptide of type II [CPII], HA, epitope 846) and catabolism (keratan sulfate [KS], COMP) [32]. Roemer et al. used MRI to identify two rare phenotypes characterised by hypertrophic and atrophic reactions of the bone with a prevalence of $0.2 \%-1.3 \%$ respectively [34]. Evidence from these papers also suggests this may constitute more than a single phenotype, including some rare variations.

\section{Mechanical overload}

Four cross sectional studies with low risk of bias and one with high risk of bias reported biomechanical factors as main mechanisms of the disease in specific KOA populations $[7,8,19,36]$. From the data extracted, these mechanisms seem responsible for the disease in $12 \%-22 \%$ of the KOA population. Waarsing et al. identified two subgroups in which biomechanical stressors appear to be responsible for the disease [8]. One subgroup was characterized by degeneration of the lateral compartment, valgus alignment, and lower BMI while a high prevalence of previous injuries (55\%), a severe degeneration of cartilage in the medial compartment and varus malalignment represent the main features in the other group. Knoop et al. and van der Esch et al. found, using cluster analysis, a phenotype with strong muscle strength, severe degeneration and low BMI [7, 36], while Bae et al. identified two subgroups of KOA patients with full thickness cartilage lesions in the medial and patella-femoral compartments [19]. Overall, this phenotype appears to be characterized by excessive mechanical forces acting on specific areas within the joint, causing KOA.

\section{Minimal joint disease}

Six studies with low risk of bias, of which three had a longitudinal design and three a cross sectional design, suggest the existence of a subgroup of KOA patients whereby the disease is characterised by low degeneration, mild clinical symptoms and slow progression over time (2-10 years) $[7-9,21,27,36]$. One further study with high risk of bias reported similar findings. Among these seven studies, a combination of magnetic resonance imaging (MRI) and biomarkers (serum cartilage oligomeric protein [sCOMP] , N-terminal propeptide of collagen IIA [PIIANP]) [21]; $x$ ray and clinical data $[9,27]$, and cluster analysis (upper leg muscle strength, body mass index (BMI), severity of radiographic OA, depressive mood, radiographic scores of OA features, regional quantitative MRI measures of cartilage and bone, and selfreported knee symptoms) $[7,36]$ were used to determine the severity of the disease. Subjects were classified in this phenotype according to the actual status of the disease and the long term outcome (2-10 years). This phenotype represents the only subgroup defined without regard to the disease aetiology. Five studies reported or allowed the 
Table 4 Appraisal of the evidence

\begin{tabular}{|c|c|c|c|c|c|c|}
\hline \multirow[b]{2}{*}{ Author/year } & \multicolumn{6}{|l|}{ Phenotypes } \\
\hline & Chronic pain & Inflammatory & Metabolic syndrome & Metabolic bone/cartilage & Mechanical overload & Minimal joint disease \\
\hline Attur 2011 [18] & & ++ & & & & \\
\hline Bae 2010 [19] & & & & & ++ & \\
\hline Berry 2010a [20] & & & & ++ & & \\
\hline Berry 2010b [21] & & & & & & ++ \\
\hline Blumnenfeld 2013 [22] & & & & ++ & & \\
\hline Cruz-Almeida 2013 [23] & ++ & & & & & \\
\hline Doss 2007 [24] & & ++ & & & & \\
\hline Egsgaard 2015 [25] & + & & & & & \\
\hline Fernández-Tajes 2014 [26] & & ++ & & & & \\
\hline Holla 2013 [27] & & & & & & ++ \\
\hline Jenkins 2015 [28] & & & & & & + \\
\hline \multicolumn{7}{|l|}{ Kerkhof 2008 [29] } \\
\hline Kinds 2013 [9] & & & & & & ++ \\
\hline King 2013 [30] & + & & & & & \\
\hline Knoop 2011 [7] & ++ & & ++ & & ++ & ++ \\
\hline Murphy 2011 [31] & ++ & & & & & \\
\hline Otterness 2000 [32] & & ++ & & ++ & & \\
\hline Pereira 2013 [33] & ++ & & & & & \\
\hline Roemer 2012 [34] & & & & ++ & & \\
\hline Sowers 2002 [35] & & & ++ & & & \\
\hline Van der Esch 2015 [36] & ++ & & ++ & & ++ & ++ \\
\hline Van Spil 2012 [37] & & ++ & ++ & & & \\
\hline Waarsing 2015 [8] & & & & ++ & ++ & ++ \\
\hline lijima 2015 [38] & & & & & + & \\
\hline Kittelson 2015 [40] & ++ & & & & & \\
\hline Total number of studies & $6(2)$ & 5 & 4 & 5 & $4(1)$ & $6(1)$ \\
\hline
\end{tabular}

+ high risk of bias, ++ low risk of bias

Total Number of Studies: low risk of bias (high risk of bias)

calculation of the prevalence in the KOA population of these features that varied between $17 \%$ and $47 \%$.

\section{Discussion}

The aim of the present study was to synthesize the current evidence for the existence of clinical phenotypes in the KOA population. Six main groups of variables which suggest the existence of different underlying disease mechanisms in the KOA population were identified after a qualitative data analysis. These sets of variables should be further explored in order to confirm and better define the KOA phenotypes emerging from the literature.

In the chronic pain phenotype, high prevalence of widespread pain and psychological disturbs suggests that central sensitization plays a fundamental role in the disease process. Severe pain is often reported in association with low or moderate degeneration of the local joint structures. In these subjects, the joint disease alone is not sufficient to explain the complex symptomatology, thus it is likely that these subjects belong to a specific KOA phenotype rather than to a stage of the disease $[7,36]$. Due to the reversibility of central sensitization combined with the lack of longitudinal studies, it is not yet clear if membership of this subgroup is stable over time. Despite this uncertainty, when patients present symptoms consistent with a chronic pain phenotype, they may need and respond to treatments that differ from those targeted towards joint pain [4]. Cognitive-behavioural therapy and pain education can be worthwhile in this phenotype and may optimize the results of other traditional intervention such as exercise therapy and joint replacement [23].

In recent years, a growing body of evidence supports the involvement of local inflammatory mediators in the disease pathogenesis [41]. Signs of inflammation have been found in a large part of the KOA population. In 
many cases these signs seem only to characterize specific phases of the disease [42]. From this literature review emerged evidence that a subgroup of the KOA subjects presents specific inflammatory mechanisms as determinant of the disease. Attur et al. identified a group of KOA subjects with a gene overexpression of inflammatory cytokines in a study with longitudinal design [18]. This finding suggests that KOA subgroups characterized by specific inflammation mechanisms may exist regardless of disease stage, as found in other studies [43, 44]. Treatments targeting the inflammation process may be particularly effective in these subjects [45].

Metabolic alterations seem key factors in two subgroups in which the alterations are present at a systemic level or with regards only to bone and cartilage metabolism in the affected knee joint [46, 47]. The included studies reporting a metabolic syndrome as key characteristic of a specific KOA subgroup used BMI; blood; and serum biomarkers in their identification process. The use of these features is supported by previous non-phenotyping studies that identified an association between high BMI and OA lesions in non-weight-bearing joints suggesting an underlying systemic pathway [48]. Moreover, recent studies showed that the combination of cardio-metabolic disturbance and obesity increases the risk of OA and identified an association between $\mathrm{OA}$ and hypertension, dyslipidaemia, and hyperglycaemia [46, 49-51]. These findings indicate that systemic metabolic alterations could be one of the main causes for the disease in a specific subgroup of subjects. A multi-stages disease model cannot fully explain the existence of a metabolic syndrome subgroup that instead could be explained as a separate KOA phenotype.

Metabolic alterations in the KOA population have been reported not only at a systemic level, but as specific alterations in cartilage and bone metabolism. Biomarker analysis represents the gold standard for the identification of metabolic alterations in bone and cartilage. The identification of specific biomarkers profiles in the KOA population, as emerged from the studies included in this review, which represents strong evidence in support of the existence of a phenotype in which bone and cartilage metabolism are of primary importance as a determinant of the disease. Drugs aiming to influence bone and cartilage metabolism may see their effect improved if tested in this specific phenotype [4].

The possibility of a mechanical overload phenotype emerged from this systematic review; however, a large gap in the evidence regarding the existence of this phenotype emerged, due also to the lack of studies with longitudinal design. Among the studies included, malalignment and muscle strength were the biomechanical variables used to define biomechanical phenotypes $[7,8,36]$ in combination with cartilage degeneration, BMI, and previous injuries. Malalignment has been shown to be strongly associated with disease progression and cartilage degeneration in specific compartments of the knee (e.g. varus malalignment is closely associated with medial tibiofemoral compartment disease) [52]; while high muscle strength has been reported as a protective factor against symptomatic but not radiographic KOA [53]. The studies included in this systematic review reported subgroups of KOA subjects with high levels of muscle strength. The authors suggested that the presence of high level of muscle strength in combination with other factors (e.g. malalignment, previous injury, BMI) could signify a group of people with high level of physical activity and biomechanical overload [8]. Therefore, malalignment in combination with other known factors (e.g. muscle strength, previous injury) may confer high local stress in the correspondent joint compartment supporting the hypothesis of biomechanical mechanisms responsible for the disease. For this reason, it is likely that these subjects would respond to, biomechanical interventions (e.g. wedged insoles, knee braces) rather than to drug treatments aiming to protect the cartilage [4].

Although our study aimed to identify phenotypes based on different disease mechanisms, from the literature a group of subjects with low degeneration and mild clinical symptoms emerged. These subjects seem to suggest the existence of a KOA subgroup characterized by minimal joint disease. Although these features could be considered representing an early stage of the disease; three of the included studies showed stability over time ( $2-10$ years) $[9,20,27]$, supporting the consideration of this subgroup as a phenotype rather than a stage of the disease. Subjects were classified in this group based on the severity and the outcome of the disease regardless of possible mechanisms or aetiology. Despite this, the clinical characteristics of the subjects classified in this subgroup seem to suggest different underling mechanisms of the disease. The inclusion of outcomes in the classification process makes the identification of subjects belonging to this phenotype difficult in clinical practice. Strong evidence of a clinical variable able to predict the nonprogression of the disease is still missing.

In this systematic review, six groups of variables that can indicate the presence of six main phenotypes have been identified. These sets of variables seem to suggest the existence of different disease mechanisms and aetiology in specific subgroups of the KOA population. None of the studies analysed here explored the possibility of an overlap between the suggested subgroups. Considering the variables used to identify phenotypes and the pathophysiology of the disease, there is no reason to exclude the possibility of an overlap. For example, patients with chronic pain could present characteristics considered key factors of other phenotypes like metabolic alterations or malalignment. Therefore, while these phenotypes may be 
distinct, they are not necessarily mutually exclusive. It can be hypothesized that patients with features consistent with more than one phenotype may be more severely affected by the disease and could be regarded as more complex clinical cases.

Another implication of the overlap between phenotypes is the possibility that the phenotypes identified here do not exist as separate entities in the KOA population, but only as result of the choice of specific variables, samples and analysis in the phenotyping process. This represents a limitation of the review that is not able to conclude if these phenotypes can be regarded as separate entities. Therefore, studies that try to identify KOA phenotypes with different disease mechanisms within the same sample are needed to study the possibility and the entity of overlap between phenotypes and verify the existence of phenotypes as distinct groups. Moreover, studies identifying an overlap between phenotypes may be important in the identification of complex KOA cases that may benefit from a combined treatment approach.

Among the 25 studies included, four had a strong risk of bias $[25,28,30]$. The main source of bias was the presence of confounding factors; of all the studies included in the review, only four studies presented a low risk of bias in that specific area [7, 8, 27, 40]. Disease duration was the main confounding factor taken into account in this systematic review, whereby differences between patients due to them being in different stages of the same disease process could potentially identify subgroups. These disease-stage subgroups did not fit the definition of phenotypes for the purpose of this review. Therefore, studies in which there were significant differences in disease duration between identified subgroups were regarded as at high risk of bias in this area.

Two of the included studies using blood and serum biomarkers in order to identify phenotypes had a mixed sample of KOA and hip OA [24,37]. In both the samples more than $70 \%$ of the subject had a diagnosis of KOA, but nevertheless findings from these studies should be interpreted with caution when applied to the KOA population.

Another important source of bias was the selection of the study sample. Studies that tried to identify specific phenotype may have oversampled high-risk patients, thus leading to elevated prevalence rates. A similar bias was the inclusion of only patients listed for joint replacement $[24,26,28]$. Furthermore, the evidence presented in this review is limited by the research focus of published studies and their quality. The criterion used to identify a phenotype required the support of two studies with low or moderate risk of bias. This approach implies the possibility that some important phenotypes have not been reported due to a limited number of appropriate studies (as was hypothesized to be the case for the mechanical overload phenotype to some extent).
Because OA is a heterogeneous disease, identifying subgroups for treatments is probably one of the promising ways forward in clinical research [2]. This can only be achieved when the correct methodology to identify such subgroups is used. For this reason, we focused only on studies that had as a main focus the identification of KOA phenotypes. Some studies looking at the influence of specific risk factors of disease progression and outcome were excluded. We are aware that results emerging from these studies may identify useful evidence, especially in generating new hypotheses regarding phenotypes. Nevertheless, the aim of this review was the identification of phenotypes which have already been broadly studied in the literature and that are supported by evidence emerging from these studies. The absence of a post traumatic KOA as an identified phenotype may work as an example. Only Waarsing et al. analysed the rate of knee injuries to characterize their phenotype. Despite the strong evidence that identifies injuries as an important risk factor in the development of KOA; studies investigating whether patients can be meaningfully grouped based on a history of traumatic injury are absent. It may be that subjects with a history of traumatic knee injury constitute a separate phenotype. Alternatively, injuries may predispose patients to KOA through more than one underlying pathway, and may therefore not be a meaningful phenotypic identifier in itself.

The lack of a clear definition of phenotypes makes synthesis of the current literature difficult; therefore, a clear and shared definition of KOA phenotypes would help to better direct future research in the field. To combine studies, we relied on what was reported by the author and on previous research on KOA risk and aetiologic factors. This approach has intrinsic risks and may be affected by a decisional bias. However, all the data used to draw the conclusions have been reported (see Additional file 1) in the attempt to make the decision process as transparent as possible. We found this methodology the best compromise to deal with the large variability in the field and to provide useful evidence. Finally, the six sets of variables identified in this review may not be able to fully explain heterogeneity of the patient population. Future research may yet lead to the identification of different disease mechanisms suggesting the existence of new phenotypes.

\section{Conclusions}

Six main sets of variables suggesting the existence of six clinical phenotypes of KOA characterized by different disease mechanisms were identified in this systematic review: chronic pain; inflammatory; metabolic syndrome; bone and cartilage metabolism; mechanical overload and minimal joint disease. This represents a good starting point for future research aiming to better identify KOA 
phenotypes. Furthermore, this process of synthesis of evidence may be relevant in the development of better treatment allocation and clinical disease management.

\section{Additional file}

Additional file 1: A. Research strategy. Table S1. Key characteristics of subgroups/phenotypes extracted from each study. Table S2. Phenotype name reported in the original paper. Table $\mathbf{S 3}$. Resume of prevalence of the different phenotypes. [7-9, 18-38, 40]. (DOCX $100 \mathrm{~kb})$

\section{Abbreviations}

BMI: Body mass index; BSP: Bone sialoprotein; COX-2: Cycloxygenase 2; ECP: Eosinophilic cationic protein; ESR: Erythrocyte sedimentation rate; HP: Hydroxylysyl pyridinoline; hsCRP: High-Sensitivity C-reactive protein IL-1ß: Interleukin-1B; IL-8: Interleukin-8; KOA: Knee osteoarthritis; KS: Keratan sulfate; LP: Lysyl pyridinoline; Mets: Metabolic syndrome; MIP-1a: Macrophage inflammatory protein-1a; MIP-1 $\beta$ : Macrophage inflammatory protein-1 $\beta$; MRI: Magnetic resonance imaging; OA: Osteoarthritis; PIIANP: N-terminal propeptide of collagen II pLeptin: Plasma leptin; pLeptin: Plasma leptin; QST: Quantitative sensory testing; sCOMP: Serum cartilage oligomeric protein; TNFI: Tumor necrosis receptor type I; TNFII: Tumor necrosis receptor type II

\section{Acknowledgments}

We would like to kindly acknowledge Martin van der Esch and Joost Dekker for their advice during the writing of the paper and the "KNEEMO - Prevention and personalized treatments in knee osteoarthritis: an Initial Training Network" for the training.

\section{Funding}

The research leading to these results has received funding from the European Union's Seventh Framework Programme (FP7-PEOPLE-2013-ITN) under grant agreement $n^{\circ} 607510$

\section{Availability of data and materials}

All of the data for this study are contained within the manuscript and its Additional file 1 .

\section{Authors' contribution}

All persons designated as authors qualify for authorship. ADI, RA, SS, SM, MS participated in the work and made substantial contributions to all of following sections below:(1) The conception and design of the study, or analysis and interpretation of data. (2) Drafting the article or revising it critically for important intellectual content. (3) Final approval of the version to be submitted. Andrea Dell'Isola (andrea.dellisola@gcu.ac.uk) takes responsibility for the integrity of this work. All authors read and approved the final manuscript.

\section{Competing interests}

The authors declare that they have no competing interests.

\section{Consent for publication}

Not applicable.

\section{Ethics approval and consent to participate}

Not applicable.

Received: 27 May 2016 Accepted: 7 October 2016

Published online: 12 October 2016

\section{References}

1. Hunter DJ, Lo GH. The management of osteoarthritis: an overview and cal to appropriate conservative treatment. Rheum Dis Clin North Am. 2008;34: 689-712.

2. Bierma-Zeinstra SM, Verhagen AP. Osteoarthritis subpopulations and implications for clinical trial design. Arthritis Res Ther. 2011:13:213. doi:10.1186/ar3299.
3. Driban JB, Sitler MR, Barbe MF, Balasubramanian E. Is osteoarthritis a heterogeneous disease that can be stratified into subsets? Clin Rheumatol. 2010;29:123-31. doi:10.1007/s10067-009-1301-1.

4. Felson DT. Identifying different osteoarthritis phenotypes through epidemiology. Osteoarthr Cartil. 2010;18:601-4. doi:10.1016/j.joca.2010.01.007.

5. Hinman RS, Crossley KM. Patellofemoral joint osteoarthritis: an important subgroup of knee osteoarthritis. Rheumatology (Oxford). 2007;46:1057-62.

6. National Institute for Health and Clinical Excellence (NICE). Osteoarthritis: Care and Management. London: NICE; 2014. Accessible at: https://www.nice. org.uk/guidance/cg177. Accessed 09 Aug 2016 (UK) NCGC.

7. Knoop J, Van Der Leeden M, Thorstensson CA, Roorda LD, Lems WF, Knol $D L$, et al. Identification of phenotypes with different clinical outcomes in knee osteoarthritis: Data from the osteoarthritis initiative. Arthritis Care Res. 2011;63:1535-42. http://dx.doi.org/10.1002/acr.20571.

8. Waarsing $J \mathrm{H}$, Bierma-Zeinstra SM, Weinans $\mathrm{H}$. Distinct subtypes of knee osteoarthritis: data from the Osteoarthritis Initiative. Rheumatology (Oxford). 2015:54:1650-8.

9. Kinds MB, Marijnissen ACA, Viergever MA, Emans PJ, Lafeber FPJG, Welsing PMJ. Identifying phenotypes of knee osteoarthritis by separate quantitative radiographic features may improve patient selection for more targeted treatment. J Rheumatol. 2013;40:891-902. http://dx.doi. org/10.3899/jrheum.121004.

10. Karsdal MA, Bihlet A, Byrjalsen I, Alexandersen P, Ladel C, Michaels M, et al. OA phenotypes, rather than disease stage, drive structural progression identification of structural progressors from 2 phase III randomized clinical studies with symptomatic knee OA. Osteoarthr Cartil. 2015;23:550-8.

11. Wesseling J, Bierma-Zeinstra SM, Kloppenburg M, Meijer R, Bijlsma JW. Worsening of pain and function over 5 years in individuals with "early" OA is related to structural damage: data from the Osteoarthritis Initiative and CHECK (Cohort Hip \& Cohort Knee) study. Ann Rheum Dis. 2015;74:347-53. doi:10.1136/annrheumdis-2013-203829.

12. Ibrahim SA, Burant CJ, Mercer MB, Siminoff LA, Kwoh CK. Older patients perceptions of quality of chronic knee or hip pain: differences by ethnicity and relationship to clinical variables. J Gerontol A, Biol Sci Med Sci. 2003; 58:M472-7

13. Riddle DL, Stratford PW. Knee pain during daily tasks, knee osteoarthritis severity, and widespread pain. Phys Ther. 2014;94:490-8. doi:10.2522/ptj. 20130331

14. Weidow J, Pak J, Karrholm J. Different patterns of cartilage wear in medial and lateral gonarthrosis. Acta Orthop Scand. 2002;73:326-9. doi:10.1080/ 000164702320155347

15. van der Esch M, Knol DL, Schaffers IC, Reiding DJ, van Schaardenburg D, Knoop J, et al. Osteoarthritis of the knee: multicompartmental or compartmental disease? Rheumatology (Oxford). 2014;53:540-6. doi:10. 1093/rheumatology/ket393.

16. Hayden JA, Cote P, Bombardier C. Evaluation of the quality of prognosis studies in systematic reviews. Ann Intern Med. 2006;144:427-37.

17. Hsieh H-F, Shannon SE. Three approaches to qualitative content analysis. Qual Health Res. 2005:15:1277-88. doi:10.1177/1049732305276687.

18. Attur M, Belitskaya-Levy I, Oh C, Krasnokutsky S, Greenberg J, Samuels J, et al. Increased interleukin-1 beta gene expression in peripheral blood leukocytes is associated with increased pain and predicts risk for progression of symptomatic knee osteoarthritis. Arthritis Rheum. 2011:63:1908-17. doi:10. 1002/art.30360.

19. Bae WC, Payanal MM, Chen AC, Hsieh-Bonassera ND, Ballard BL, Lotz MK, et al. Topographic Patterns of Cartilage Lesions in Knee. Osteoarthr Cartil. 2010;1:10-9. doi:10.1177/1947603509354991.

20. Berry PA, Maciewicz RA, Cicuttini FM, Jones MD, Hellawell CJ, Wluka AE. Markers of bone formation and resorption identify subgroups of patients with clinical knee osteoarthritis who have reduced rates of cartilage loss. J Rheumatol. 2010;37:1252-9. doi:10.3899/jrheum.091055.

21. Berry PA, Maciewicz RA, Wluka AE, Downey-Jones MD, Forbes A, Hellawell CJ, et al. Relationship of serum markers of cartilage metabolism to imaging and clinical outcome measures of knee joint structure. Ann Rheum Dis. 2010;69:1816-22. doi:10.1136/ard.2009.124420

22. Blumenfeld O, Williams FMK, Hart DJ, Spector TD, Arden N, Livshits G. Association between cartilage and bone biomarkers and incidence of radiographic knee osteoarthritis (RKOA) in UK females: A prospective study. Osteoarthr Cartil. 2013;21:923-9. doi:10.1016/j.joca.2013.04.009.

23. Cruz-Almeida Y, King CD, Goodin BR, Sibille KT, Glover TL, Riley JL, et al. Psychological profiles and pain characteristics of older adults with knee 
osteoarthritis. Arthritis Care Res (Hoboken). 2013;65:1786-94. doi:10.1002/ acr.22070.

24. Doss F, Menard J, Hauschild M, Kreutzer H-JJ, Mittlmeier T, Müller-Steinhardt $M$, et al. Elevated IL-6 levels in the synovial fluid of osteoarthritis patients stem from plasma cells. Scand J Rheumatol. 2007;36:136-9.

25. Egsgaard LL, Eskehave TN, Bay-Jensen AC, Hoeck HC, Arendt-Nielsen L. Identifying specific profiles in patients with different degrees of painful knee osteoarthritis based on serological biochemical and mechanistic pain biomarkers: a diagnostic approach based on cluster analysis. Pain. 2015;156: 96-107. doi:10.1016/j.pain.0000000000000011.

26. Fernandez-Tajes J, Soto-Hermida A, Vazquez-Mosquera ME, Cortes-Pereira E, Mosquera A, Fernandez-Moreno M, et al. Genome-wide DNA methylation analysis of articular chondrocytes reveals a cluster of osteoarthritic patients. Ann Rheum Dis. 2014;73:668-77. doi:10.1136/annrheumdis-2012-202783.

27. Holla JF, van der Leeden M, Heymans MW, Roorda LD, Bierma-Zeinstra SM, Boers M, et al. Three trajectories of activity limitations in early symptomatic knee osteoarthritis: a 5-year follow-up study. Ann Rheum Dis. 2014;73:1369-75. doi:10.1136/annrheumdis-2012-202984.

28. Jenkins JB, McCoy TP. Symptom clusters, functional status, and quality of life in older adults with osteoarthritis. Orthop Nurs. 2015;34:34-6. doi:10.1097/ NOR.0000000000000112.

29. Kerkhof JM, Uitterlinden AG, Valdes AM, Hart DJ, Rivadeneira F, Jhamai M, et al. Radiographic osteoarthritis at three joint sites and FRZB, LRP5, and LRP6 polymorphisms in two population-based cohorts. Osteoarthr Cartil. 2008;16: 1141-9. doi:10.1016/j.joca.2008.02.007.

30. King CD, Sibille KT, Goodin BR, Cruz-Almeida Y, Glover TL, Bartley E, et al. Experimental pain sensitivity differs as a function of clinical pain severity in symptomatic knee osteoarthritis. Osteoarthr Cartil. 2013;21:1243-52. doi:10. 1016/j.joca.2013.05.015

31. Murphy SL, Lyden AK, Phillips K, Clauw DJ, Williams DA. Subgroups of older adults with osteoarthritis based upon differing comorbid symptom presentations and potential underlying pain mechanisms. Arthritis Res Ther. 2011;13:R135. doi:10.1186/ar3449.

32. Otterness IG, Swindell AC, Zimmerer RO, Poole AR, lonescu M, Weiner E. An analysis of 14 molecular markers for monitoring osteoarthritis: segregation of the markers into clusters and distinguishing osteoarthritis at baseline. Osteoarthr Cartil. 2000;8:180-5. doi:10.1053/joca.1999.0288.

33. Pereira D, Severo M, Barros H, Branco J, Santos RA, Ramos E. The effect of depressive symptoms on the association between radiographic osteoarthritis and knee pain: a cross-sectional study. BMC Musculoskelet Disord. 2013;14:214. doi:10.1186/1471-2474-14-214.

34. Roemer FW, Guermazi A, Niu J, Zhang Y, Mohr A, Felson DT. Prevalence of magnetic resonance imaging-defined atrophic and hypertrophic phenotypes of knee osteoarthritis in a population-based cohort. Arthritis Rheum. 2012:64:429-37. doi:10.1002/art.33344.

35. Sowers M, Jannausch M, Stein E, Jamadar D, Hochberg M, Lachance L. Creactive protein as a biomarker of emergent osteoarthritis. Osteoarthr Cartil. 2002;10:595-601.

36. van der Esch $M$, Knoop J, van der Leeden M, Roorda LD, Lems WF, Knol DL, et al. Clinical phenotypes in patients with knee osteoarthritis: a study in the Amsterdam osteoarthritis cohort. Osteoarthr Cartil. 2015;23:544-9. doi:10. 1016/j.joca.2015.01.006

37. van Spil WEE, Jansen NWDW, Bijlsma JWJW, Reijman M, DeGroot J, Welsing PMJM, et al. Clusters within a wide spectrum of biochemical markers for osteoarthritis: data from CHECK, a large cohort of individuals with very early symptomatic osteoarthritis. Osteoarthr Cartil. 2012;20:745-54. doi:10.1016/j. joca.2012.04.004

38. lijima H, Fukutani N, Aoyama T, Fukumoto T, Uritani D, Kaneda E, et al. Clinical Phenotype Classifications Based on Static Varus Alignment and Varus Thrust in Japanese Patients With Medial Knee Osteoarthritis. Arthritis Rheumatol (Hoboken, NJ). 2015;67:2354-62. doi:10.1002/art.39224.

39. Baert IA, Mahmoudian A, Nieuwenhuys A, Jonkers I, Staes F, Luyten FP, et al. Proprioceptive accuracy in women with early and established knee osteoarthritis and its relation to functional ability, postural control, and muscle strength. Clin Rheumatol. 2013;32:1365-74. doi:10.1007/s10067-013-2285-4.

40. Kittelson AJ, Stevens-Lapsley JE, Schmiege SJ. Determination of Pain Phenotypes in Knee Osteoarthritis: A Latent Class Analysis using Data from the Osteoarthritis Initiative Study. Arthritis Care Res (Hoboken). 2015. doi:10. 1002/acr.22734.

41. Pelletier JP, Martel-Pelletier J, Abramson SB. Osteoarthritis, an inflammatory disease: potential implication for the selection of new therapeutic targets.
Arthritis Rheum. 2001;44:1237-47. doi:10.1002/1529-0131(200106)44:6 < 1237: AID-ART214 > 3.0.CO;2-F [doi].

42. Benito MJ, Veale DJ, FitzGerald O, van den Berg WB, Bresnihan B. Synovial tissue inflammation in early and late osteoarthritis. Ann Rheum Dis. 2005; 64:1263-7.

43. Haywood L, McWilliams DF, Pearson Cl, Gill SE, Ganesan A, Wilson D, et al. Inflammation and angiogenesis in osteoarthritis. Arthritis Rheum. 2003;48: 2173-7. doi:10.1002/art.11094.

44. Smith MD, Triantafillou S, Parker A, Youssef PP, Coleman M. Synovial membrane inflammation and cytokine production in patients with early osteoarthritis. J Rheumatol. 1997:24:365-71.

45. McCabe PS, Parkes MJ, Maricar N, Hutchinson CE, Freemont A, O'Neill TW, et al. Synovial Fluid White Cell Count in Knee Osteoarthritis: Association with Structural Findings and Treatment Response. NJ): Arthritis Rheumatol (Hoboken; 2016. doi:10.1002/art.39829.

46. Lee S, Kim TN, Kim SH, Kim YG, Lee CK, Moon HB, et al. Obesity, metabolic abnormality, and knee osteoarthritis: a cross-sectional study in Korean women. Mod Rheumatol. 2015;25:292-7. doi:10.3109/14397595.2014.939393.

47. Hardcastle SA, Dieppe P, Gregson CL, Arden NK, Spector TD, Hart DJ, et al. Individuals with high bone mass have an increased prevalence of radiographic knee osteoarthritis. Bone. 2015;71:171-9. doi:10.1016/j.bone. 2014.10.015

48. Yusuf E, Nelissen RG, loan-Facsinay A, Stojanovic-Susulic V, DeGroot J, van Osch $\mathrm{G}$, et al. Association between weight or body mass index and hand osteoarthritis: a systematic review. Ann Rheum Dis. 2010;69:761-5. doi:10. 1136/ard.2008.106930.

49. Eymard F, Parsons C, Edwards MH, Petit-Dop F, Reginster JY, Bruyere O, et al. Diabetes is a risk factor for knee osteoarthritis progression. Osteoarthr Cartil. 2015;23(6):851-9.

50. Sowers M, Karvonen-Gutierrez CA, Palmieri-Smith R, Jacobson JA, Jiang $Y$, Ashton-Miller JA. Knee osteoarthritis in obese women with cardiometabolic clustering. Arthritis Rheum. 2009;61:1328-36. doi:10.1002/art.24739.

51. Zhuo Q, Yang W, Chen J, Wang Y. Metabolic syndrome meets osteoarthritis. Nat Rev. 2012;8:729-37. doi:10.1038/nrrheum.2012.135.

52. Sharma L, Song J, Felson DT, Cahue S, Shamiyeh E, Dunlop DD. The role of knee alignment in disease progression and functional decline in knee osteoarthritis. JAMA. 2001:286:188-95.

53. Segal NA, Glass NA, Felson DT, Hurley M, Mei Y, Nevitt M, et al. Effect of Quadriceps Strength and Proprioception on Risk for Knee Osteoarthritis. Med Sci Sport Exerc. 2010;42:2081-8. doi:10.1249/MSS.0b013e3181dd902e.

\section{Submit your next manuscript to BioMed Central and we will help you at every step:}

- We accept pre-submission inquiries

- Our selector tool helps you to find the most relevant journal

- We provide round the clock customer support

- Convenient online submission

- Thorough peer review

- Inclusion in PubMed and all major indexing services

- Maximum visibility for your research

Submit your manuscript at www.biomedcentral.com/submit 